\title{
Biophysical Feedbacks in the Tropical Pacific
}

\author{
Ben MARZEion* AND AXEl TimmermanN ${ }^{+}$ \\ Leibniz-Institut für Meereswissenschaften, Kiel, Germany \\ Ragu Murtugudde \\ ESSIC, University of Maryland, College Park, College Park, Maryland \\ FEI-FEI JIN \# \\ SOEST, University of Hawaii at Manoa, Honolulu, Hawaii
}

(Manuscript received 9 September 2003, in final form 16 June 2004)

\begin{abstract}
This study explores the influence of phytoplankton on the tropical Pacific heat budget. A hybrid coupled model for the tropical Pacific that is based on a primitive equation reduced-gravity multilayer ocean model, a dynamic ocean mixed layer, an atmospheric mixed layer, and a statistical atmosphere is used. The statistical atmosphere relates deviations of the sea surface temperature from its mean to wind stress anomalies and allows for the rectification of the annual cycle and the El Niño-Southern Oscillation (ENSO) phenomenon through the positive Bjerknes feedback. Furthermore, a nine-component ecosystem model is coupled to the physical variables of the ocean. The simulated chlorophyll concentrations can feed back onto the ocean heat budget by their optical properties, which modify solar light absorption in the surface layers. It is shown that both the surface layer concentration as well as the vertical profile of chlorophyll have a significant effect on the simulated mean state, the tropical annual cycle, and ENSO. This study supports a previously suggested hypothesis (Timmermann and Jin) that predicts an influence of phytoplankton concentration of the tropical Pacific climate mean state and its variability. The bioclimate feedback diagnosed here works as follows: Maxima in the subsurface chlorophyll concentrations lead to an enhanced subsurface warming due to the absorption of photosynthetically available shortwave radiation. This warming triggers a deepening of the mixed layer in the eastern equatorial Pacific and eventually a reduction of the surface ocean currents (Murtugudde et al.). The weakened south-equatorial current generates an eastern Pacific surface warming, which is strongly enhanced by the Bjerknes feedback. Because of the deepening of the mixed layer, the strength of the simulated annual cycle is also diminished. This in turn leads to an increase in ENSO variability.
\end{abstract}

\section{Introduction}

The heat budget of the tropical Pacific mixed layer can be decomposed into advective heating, turbulent fluxes at its base, air-sea fluxes, and radiant heating due

\footnotetext{
* Current affiliation: Nansen Environmental and Remote Sensing Center, Bergen, Norway.

+ Current affiliation: IPRC, SOEST, University of Hawaii at Manoa, Honolulu, Hawaii.

\# Current affiliation: Department of Meteorology, The Florida State University, Tallahassee, Florida.
}

Corresponding author address: Axel Timmermann, IPRC, SOEST, University of Hawaii, 2525 Correa Rd., Honolulu, HI 96822.

E-mail: axel@hawaii.edu to the absorption of shortwave incoming radiation. Radiant heating is determined by surface solar irradiance fluxes and the optical properties of seawater and its biogenic compounds. Ocean optical studies (e.g., Lewis et al. 1983) have revealed that chlorophyll plays a crucial part in attenuating light in the euphotic zone of the ocean. Hence, chlorophyll serves as a vertical redistributor of radiant heating, while keeping the total amount of heating nearly constant. This leads to changes in mixed layer buoyancy fluxes and temperatures. So far, this effect has not been taken into account by realistic, coupled climate model simulations, which suffer from systematic biases in tropical temperatures.

Recent coupled general circulation model (CGCM) intercomparison projects (AchutaRao and Sperber 2002; Latif et al. 2001) have revealed that all of these models have serious difficulties in simulating the mean state as well as the annual cycle in the tropical Pacific 
realistically. ${ }^{1}$ Still, their representation of ENSO variability is getting better and better. ENSO variability, the annual cycle, and the climatic mean state are all strongly controlled by the Bjerknes feedback (Bjerknes 1969). For an appropriate representation of all three, it is likely that more effort has to be put forward to incorporate important processes that have not been taken into consideration so far. Two important oceanic elements are not captured in state-of-the-art CGCM simulations: tropical instability waves, which contribute up to $2 \mathrm{~K}$ month ${ }^{-1}$ heating to the eastern tropical Pacific heat budget (Kessler et al. 1998; Vialard et al. 2001), as well as spatiotemporal variations in the attenuation of light in the surface ocean. The former may depend largely on the ocean model resolution. However the latter involves improvements of the model physics. Our study focuses on the latter.

Previously the effect of chlorophyll pigment concentrations on the tropical Pacific heat budget has been studied using observational data (Lewis et al. 1990; Sathyendranath et al. 1991; Strutton and Chavez 2004) as well as ocean models (Nakamoto et al. 2001; Murtugudde et al. 2002). The ocean model studies so far neglected full atmosphere-ocean coupling and the time-dependence of phytoplankton concentrations. The results were contradictory. While Nakamoto et al. (2001) simulated a cooling due to enhanced trapping of solar radiation in the surface layers, Murtugudde et al. (2002) found a warming tendency in the eastern equatorial Pacific. So far it has not been resolved as to whether this discrepancy arose from different coupling strategies, or whether it represents the different reference attenuation depths used in these two studies. Another important fact is that phytoplankton concentrations in the tropical Pacific are also strongly timedependent. They are influenced by interannual climate variations in the tropical Pacific (Cowles and Barber 1977; Murtugudde et al. 1999; Chavez et al. 1998, 1999; Leonard and McClain 1996) which modulate the nutrient supply both through horizontal and vertical advection, and the occurence of tropical instability waves.

In order to study the influence of space- and timevarying chlorophyll concentrations on the surface heat budget of the eastern equatorial Pacific we will use a novel hybrid coupled atmosphere-ocean-ecosystem model, which is described in section 2. Section 3 discusses the influence of ocean biology on the climate mean state of the tropical Pacific. In section 4 it is revealed that the strength of the annual cycle in the equatorial Pacific is strongly dependent on the radiant heating due to chlorophyll. Section 5 briefly describes the response of ENSO to ocean biology in our coupled atmosphere-ocean-ecosystem model. The role of the positive Bjerknes feedback on the biophysical coupling

\footnotetext{
${ }^{1}$ In the tropical Atlantic the average performance is even worse.
}

in the tropical Pacific will be discussed in section 6. A summary of the main results and a discussion of their relevance for coupled climate modeling is given in section 7 .

\section{Model description}

The tropical Pacific reduced-gravity ocean model (Gent and Cane 1989) is based on the primitive equations and uses $15 \sigma$ layers and an explicit mixed layer formulation (Chen et al. 1994) which accounts for mixing due to shear instabilities. The ocean model domain extends from $30^{\circ} \mathrm{N}$ to $30^{\circ} \mathrm{S}$. The model is driven by heat and freshwater fluxes partly diagnosed from a simple atmospheric mixed layer model (Seager et al. 1988; Murtugudde et al. 1996). Shortwave radiation and precipitation are monthly climatologically prescribed. Furthermore, anomalous wind stress forcing is applied which is derived from a linear statistical atmosphere (Burgers and van Oldenborgh 2003), using a linear regression of monthly observed Florida State University (FSU) wind stress data (Stricherz et al. 1997) to observed Niño-3 (area-weighted average of the region: $5^{\circ} \mathrm{S}-5^{\circ} \mathrm{N}, 150^{\circ}-90^{\circ} \mathrm{W}$ ) and Niño-4 (area-weighted average of the region: $5^{\circ} \mathrm{S}-5^{\circ} \mathrm{N}, 150^{\circ} \mathrm{W}-160^{\circ} \mathrm{E}$ ) sea surface temperature anomalies (SSTA) from the Kaplan extended dataset (Kaplan et al. 1998). This simple atmospheric model captures the positive Bjerknes feedback (Bjerknes 1969). The corresponding wind stress regressions are depicted in Fig. 1. The regression patterns represent the trade wind changes in response to a positive eastern and a positive western equatorial Pacific SSTA, respectively. An important component of these wind stress patterns is the wind stress curl in offequatorial regions, which generates oceanic Rossby waves and leads to a recharge and discharge of the equatorial heat content during a La Niña or an El Niño event, respectively. The linear relationship between SST anomalies and the wind stress patterns is formulated in terms of

$$
\begin{aligned}
\tau_{\text {model }}= & \tau_{\text {clim }}+\delta \cdot\left(\text { Niño3 } \cdot \tau_{\text {stat }_{\text {Nino3 }}}\right. \\
& \left.+ \text { Niño4 } \cdot \tau_{\text {stat }_{\text {Nino } 4}}\right),
\end{aligned}
$$

where $\delta$ represents the so-called coupling strength. Niño-3 and Niño-4 are the SSTA anomalies in their respective areas and $\tau_{\text {stat }_{\text {Nino3 }}}, \tau_{\text {stat }_{\text {Nino }}}$ represent the wind stress regression pattern shown in Fig. 1. The wind stress climatology $\tau_{\text {clim }}$ is added in order to obtain the total wind stress field. The wind stress anomalies are diagnosed by multiplying the regression patterns of Fig. 1 with their corresponding eastern or western equatorial Pacific SST anomalies. The SST anomalies are computed with respect to the time-averaged SST field from the uncoupled simulation. This choice implies that the annual SST variations can be amplified by the Bjerknes feedback as suggested in the studies of Xie $(1994,1996)$. It is well known (Eckert 1998; Flügel 1994) that hybrid 


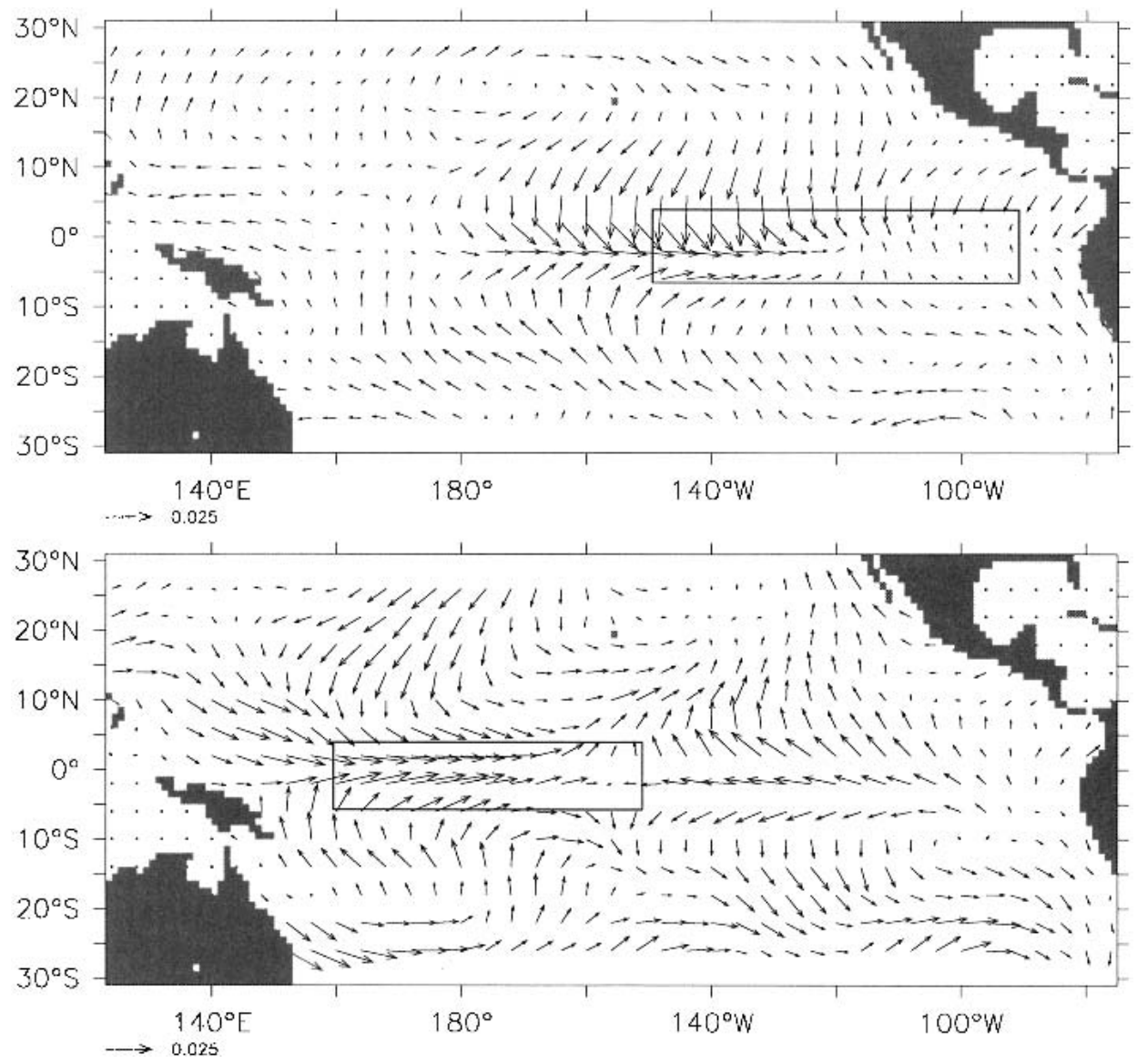

FIG. 1. Wind stress regression patterns $\left(\mathrm{Pa} \mathrm{K}^{-1}\right.$ ) for the (top) Niño-3 and (bottom) Niño-4 SST anomalies, with boxes indicating (top) Niño-3 and (bottom) Niño-4 regions.

coupled models (OGCM + statistical atmosphere) generate self-sustained ENSO oscillations, when the coupling strength between wind stress anomalies and SST anomalies is typically larger than one. In our case, selfsustained ENSO oscillations arise when $\delta \sim 1.4$. Due to the ongoing debate (Kessler 2002) as to whether ENSO is self-sustained oscillation or a damped noise-driven oscillatory mode, we choose a coupling strength close to the critical bifurcation point for self-sustained oscillations. In our simulations $\delta$ is chosen to be 1.5.

Radiant heating is represented by a two-component (clear water, chlorophyll) empirical model, which is similar to that of Morel (1988) over the range of parameters used in this study. We assume a constant albedo and monthly climatological solar irradiance, interannual variations of shortwave radiation caused by changes in convective cloudiness are not included in the forcing. The depth-dependent light attenuation coefficient $k_{E}$ for the visible part of the radiation, which is assumed to be $50 \%$ of the total incident flux, is computed from chlorophyll concentrations as in

$$
k_{E}=k_{W}+\gamma \times a_{\mathrm{Chl}} \times C^{b \mathrm{Chl}},
$$

where $k_{W}=0.027 \mathrm{~m}^{-1}$ is the attenuation coefficient for seawater; $C$ denotes the chlorophyll concentration in $\mathrm{mg} \mathrm{m}^{-3}$, and $a_{\mathrm{Chl}}=0.0518 \mathrm{~m}^{-1}$ and $b_{\mathrm{Chl}}=0.4280$ are empirical coefficients (Murtugudde et al. 2002). The remaining part of the solar radiation is assumed to be attenuated within the first few centimeters of the mixed layer. The parameter $\gamma$ quantifies how strong chlorophyll concentrations feed back onto the heat budget. It is referred to as the biological coupling coefficient. This approach to represent the optical effects of biogenic matter in seawater results from a simplification of the irridiance divergence, and does not take into account the dependence on wavelength, but is a rather good approximation for chlorophyll concentrations $\leq 0.5 \mathrm{mg}$ $\mathrm{m}^{-3}$. The case $\gamma=0$ will be referred to as the nobiology case, in contrast to the full-biology case with $\gamma$ $=1.0$. In state-of-the-art CGCM simulations, biology is often represented by a larger $k_{W}$, denying spatial and temporal variability, or incoming radiation is assumed to be attenuated completely within the mixed layer, for example, $k_{E}=\infty$. Other models simply use clear water attenuation depth. Here, we will discuss coupled atmosphere-ocean experiments performed with a hy- 


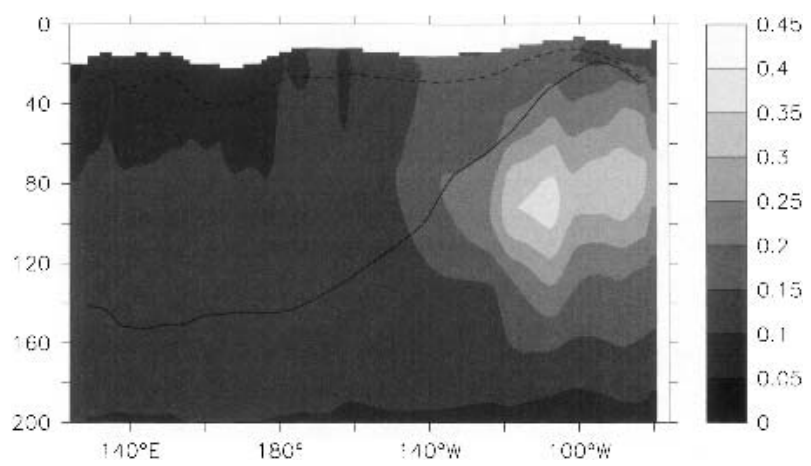

FIG. 2. Vertical chlorophyll $\left(\mathrm{mg} \mathrm{m}^{-3}\right)$ section along the equator for $\gamma=0$. The dashed line represents the base of the mixed layer, and the solid line the thermocline $\left(20^{\circ} \mathrm{C}\right)$ isotherm. For all equatorial sections in this paper, data were averaged between $2.5^{\circ} \mathrm{S}$ and $2.5^{\circ} \mathrm{N}$

brid coupled tropical model in which $\gamma$ is varied from 0 to 1 .

The nine-component ecosystem model, which is coupled to the ocean model, is based on the assumption that the tropical Pacific is an iron- and nitrogen-limited environment. Further details about the ecosystem model and its coupling to the physical variables of the ocean model can be found in Christian et al. (2001a,b).

\section{Mean state changes}

In a first set of experiments we vary the biological coupling coefficient $\gamma$ from 0 to 1 , while keeping the atmosphere-ocean coupling coefficient $\delta=1.5$ constant.

Figures 2 and 3 display the positions of the mixed layer (dashed) and the $20^{\circ} \mathrm{C}$ isotherm (solid), representing the thermocline depth, as well as the chlorophyll concentration in a vertical section along the equator for one experiment without (Fig. 2) bio-optical coupling $(\gamma=0)$ and one with $\gamma=1$ (Fig. 3). For $\gamma=1.0$ the depth of the thermocline is too shallow in the warm

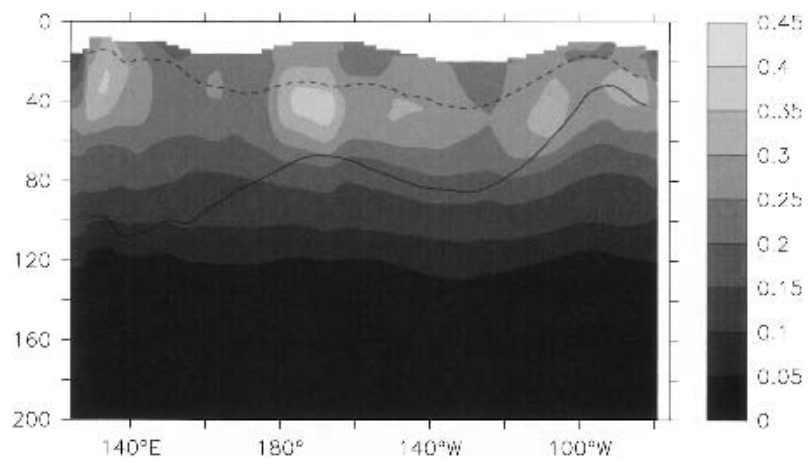

FIG. 3. The same as in Fig. 2 except for $\gamma=1$.

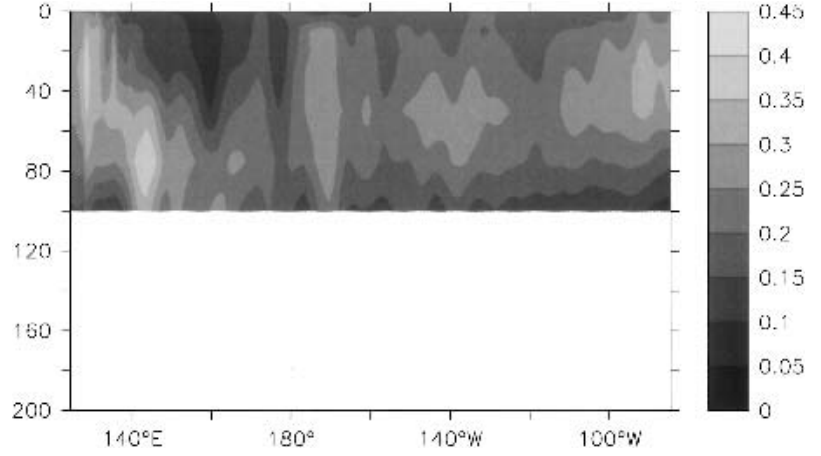

FIG. 4. Vertical chlorophyll $\left(\mathrm{mg} \mathrm{m}^{-3}\right)$ section along the equator from the observations. Data are obtained online at http:// www.nodc.-noaa.gov/General/chloro.html.

pool area, ${ }^{2}$ as compared to observations. We clearly see that for $\gamma=1$ the chlorophyll maximum comes closer to the surface in the eastern equatorial Pacific and spreads out along the equatorial Pacific. Phytoplankton are thriving in those zones that are characterized by optimal nutrient and light availability. For $\gamma=1$ much less radiation reaches depths of $80-100 \mathrm{~m}$, in contrast to the situation with $\gamma=0$. Hence bio-optical coupling prevents the generation of a deep chlorophyll maximum zone. Moreover, in Fig. 3 we see that the phytoplankton maximum in the eastern equatorial Pacific is located just below the mixed layer and above the thermocline. As can be seen from Fig. 4, the case $\gamma=1$ resembles the observed chlorophyll profile much more than the case $\gamma$ $=0$. We see further that for $\gamma=1$, more light is attenuated close to the base of the mixed layer, thereby deepening the mixed layer in the east Pacific (Figs. 5 and 6) due to positive buoyancy forcing. This deepening changes the zonal density gradient along the equator, which leads to a weaker advection, and it changes the off-equatorial density gradient, which changes the geostrophic balance. Thereby, the lateral temperature advection is reduced (Fig. 7). The result is a net warming of the eastern equatorial Pacific. Similar results were obtained by Murtugudde et al. (2002) using a forced ocean model simulation. In our case the warming tendency will be amplified further by coupled airsea interactions. From Fig. 7 we diagnose a net ocean dynamical warming of the eastern equatorial Pacific of about $2-3 \mathrm{~K} \mathrm{month}^{-1}$. In addition to this indirect warming effect there is a direct thermal effect that originates from the direct attenuation of photosynthetically available radiation in the mixed layer (Timmermann and Jin 2002). This separation into direct and indirect effect has already been used by Murtugudde et al. (2002). In our

\footnotetext{
${ }^{2}$ This misrepresentation originates from the structure of our two-pattern statistical atmosphere. Further analysis with a more complex statistical atmosphere is underway to improve this model caveat.
} 


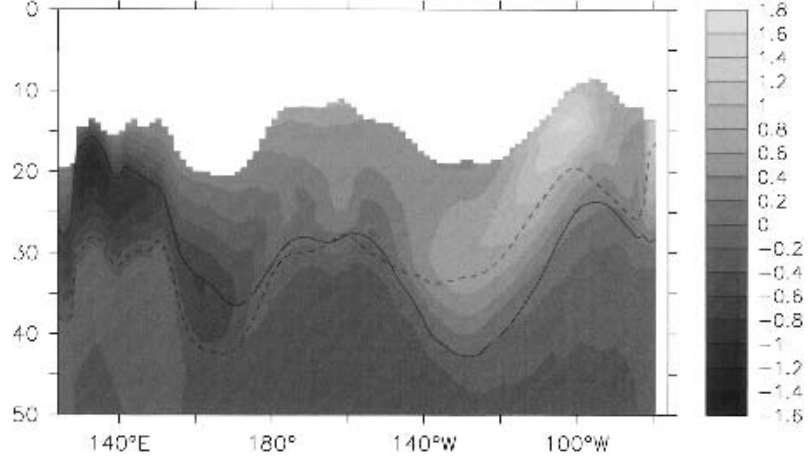

FIG. 5. Equatorial section of mixed layer depth for $\gamma=1$ (solid line) and $\gamma=0$ (dashed line); equatorial section of the difference of radiant heating between $\gamma=1$ and $\gamma=0$ (shaded). Radiant heating $\left(\mathrm{K} \mathrm{month}^{-1}\right)$ is computed by subtracting the absorbed shortwave radiation within the individual layers from the incoming radiation at the top of the layer. It is assumed that $50 \%$ of the incoming shortwave radiation at the surface is absorbed within the upper centimeters of the water column.

case the direct biothermal coupling leads to a net warming of the upper eastern equatorial Pacific by about $1-2$ $\mathrm{K}$ month ${ }^{-1}$ (see Fig. 5). The simulated magnitude of the direct effect compares fairly well with recent observational estimates of Lewis et al. (1990), Strutton and Chavez (2004), and the modeling study of Timmermann and Jin (2002).

Both effects together lead to a warming of the eastern equatorial Pacific by $2 \mathrm{~K}$ (Fig. 8), which in turn weakens the equatorial trade winds (Fig. 1). Weakened equatorial winds are associated with a discharge of warm pool waters and a reduction of the equatorial upwelling in the eastern Pacific. Eventually, the warm

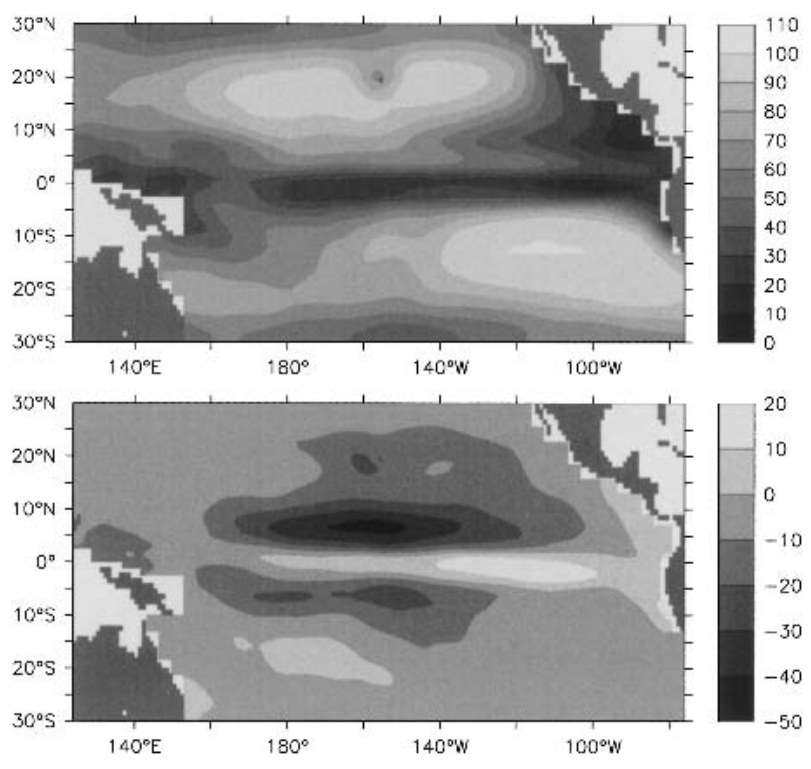

FIG. 6. (top) Mean mixed layer depth (m) for $\gamma=0$; (bottom) $\operatorname{MLD}(\gamma=1.0)-\operatorname{MLD}(\gamma=0)(\mathrm{m})$. Here, $\delta$ is chosen to be 1.5.

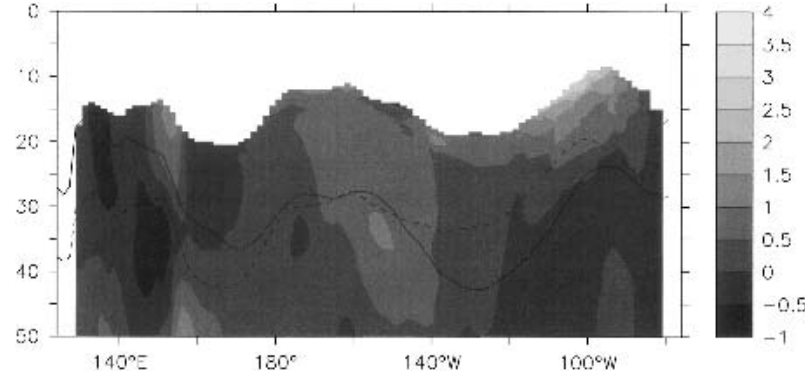

FIG. 7. The same as in Fig. 5 except for equatorial section of the difference of horizontal temperature advection $\left(\mathrm{K} \mathrm{month}^{-1}\right)$ between $\gamma=1$ and $\gamma=0$ (shaded).

pool area cools down, whereas the eastern equatorial Pacific warms even further. A cooling of the warm pool area is accompanied by an intensification of the equatorial trades in the western Pacific (see Fig. 1), thereby inducing anomalous upwelling in the warm pool area. This leads to an enhancement of iron and nitrate concentrations in the warm pool and subsequently to higher phytoplankton concentrations (see Fig. 3). A similar mechanism has been suggested in Murtugudde et al. (1999) for a strong El Niño event. Finally, the cooling of the warm pool area reduces the trade winds in the eastern equatorial Pacific (see Fig. 1), thereby reducing ocean mixing and upwelling. Hence, the cooling in the warm pool area will amplify the initial biological warming in the eastern equatorial Pacific.

Thus, the Bjerknes positive air-sea feedback is an important component in setting up the oceanic thermal response to initial biological heating, as already conjec-

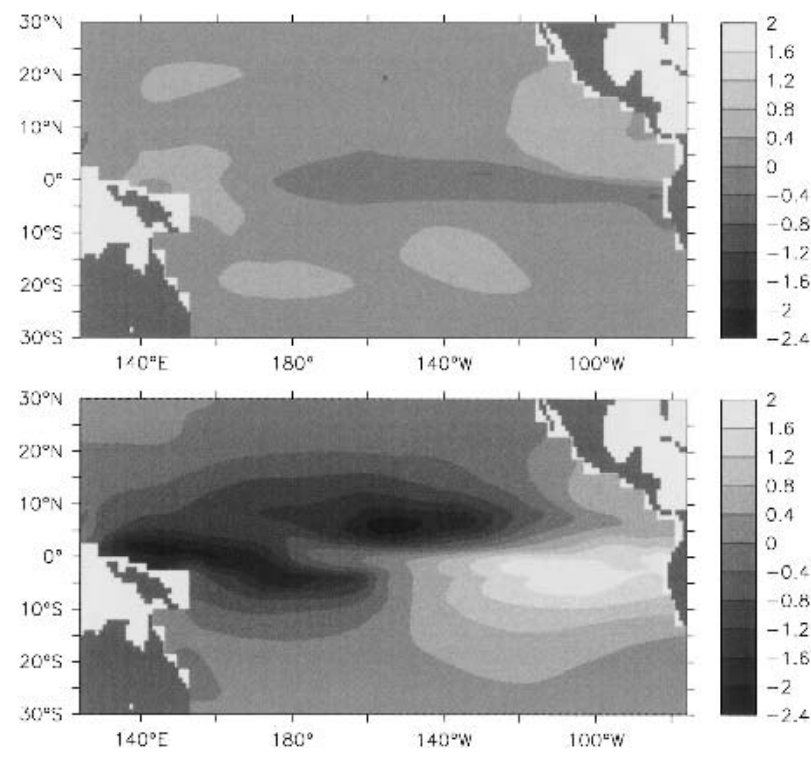

FIG. 8. (top) Difference in SST (K) between the uncoupled $(\delta=$ 0 ) simulation with and without ocean biology. (bottom) Difference in SST $(\mathrm{K})$ between the coupled $(\delta=1.5)$ simulation with and without ocean biology. 


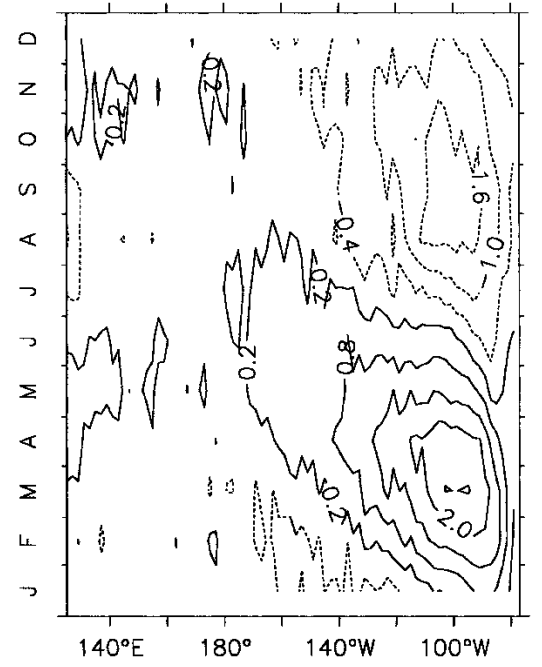

FIG. 9. Observed annual cycle for equatorial surface temperatures from the COADS dataset.

tured by Murtugudde et al. (2002) and Timmermann and Jin (2002). It is apparent that forced ocean experiments such as those performed by Nakamoto et al. (2001) are not able to capture this remote amplification effect.

\section{Influence on tropical annual cycle}

The strength of the annual cycle is sensitive to the mean depth of the mixed layer (Xie 1994). The deeper the mixed layer and the higher the thermal inertia and heat capacity, the smaller is the influence of the annual wind anomalies in generating surface temperature variations. When the mean mixed layer depth is increased, as in the case with $\gamma=1$, the efficiencies of oceanic mixing, evaporative cooling, and Ekman upwelling are strongly diminished, thereby reducing the annual cycle amplitude. The observed annual cycle of equatorial temperatures is depicted in Fig. 9. One observes a clear westward propagation of the anomalies, which can be explained in terms of coupled air-sea feedbacks (Xie 1994; Li and Philander 1996). The warmest month is March, the coldest one September. In comparison with the observed annual cycle, the simulated amplitude as well as the pronounced westward propagation of the annual cycle for $\gamma=0$ (Fig. 10) are overestimated. In addition, the strongest warming occurs in July, rather than in March. Increasing the biophysical coupling to $\gamma=1.0$ leads to some improvement of the simulated annual cycle, although the seeding temperature anomaly occurs too far east and the amplitude is underestimated. In general, an increase of the biophysical coupling coefficient $\gamma$ leads to a reduction of the annual cycle strength in the eastern equatorial Pacific. This confirms a recent finding by Schneider and Zhu (1998) who diagnosed an important sensitivity of the amplitude of the annual cycle to sunlight penetration, although the physical mechanisms differ significantly.

In addition, it can be shown that also the annual mixed layer depth variability is sensitive to biothermal coupling. Increasing $\gamma$ from 0 to 1 leads to a reduction of the range of the annual mixed layer depth variations from 35 to $20 \mathrm{~m}$ (not shown).

\section{Influence on ENSO}

One goal of our study is to test the biothermostat hypothesis of Timmermann and Jin (2002), which was originally deduced from a low-order coupled model without explicit ecosystem dynamics. In Timmermann and Jin (2002), vertical processes associated with a shift of the position of the chlorophyll maximum were not captured appropriately. In order to reassess the influence of chlorophyll on ENSO we focus here on the effect of changes in the light attenuation and the mixed layer depth due to the biophysical coupling and the vertical reorganization of the chlorophyll field.
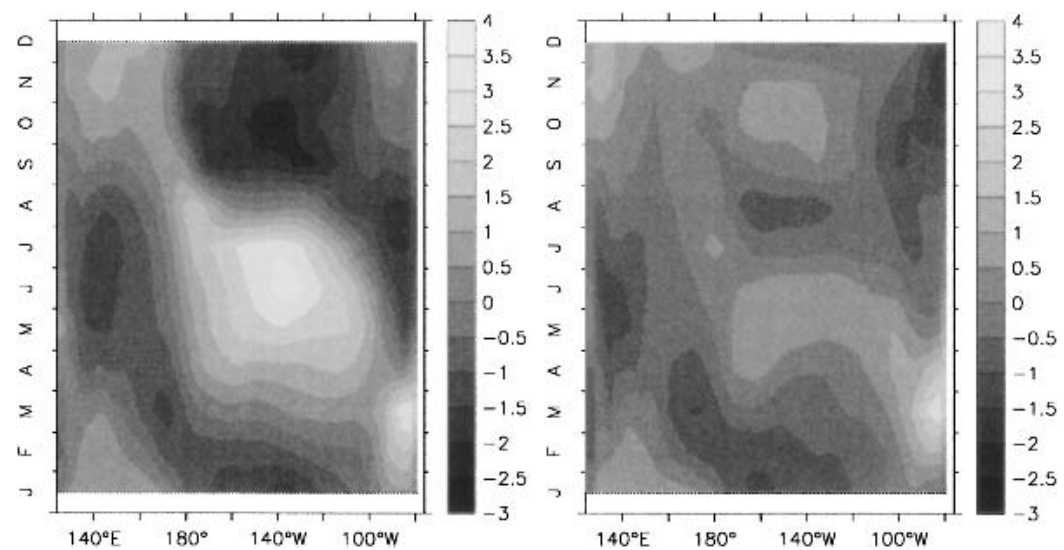

FIG. 10. Annual cycle for equatorial surface temperatures for $\delta=1.5$, (left) $\gamma=0.0$ and (right) 1.0. 
According to the ENSO recharge theory of Jin (1997), self-sustained ENSO oscillations originate from an interplay of the positive Bjerknes air-sea feedback and a delayed negative feedback associated with the recharging and discharging of equatorial thermocline waters. During a mature El Niño event one observes reduced trade winds and a wind stress curl between equatorial and off-equatorial regions. It is the zonally integrated Sverdrup transport derived from the wind stress curl that leads to a discharging of the equatorial heat content. The thermocline gets shallower and mean upwelling induces a cooling tendency, which leads to the generation of a weak La Niña event. The La Niña event is amplified by an increase of the equatorial trade winds and an enhanced upwelling of cold subsurface waters. In turn the associated zonally integrated Sverdrup transport leads to a recharging of the equatorial heat content, thereby generating a warm sea surface temperature anomaly and completing one ENSO cycle. The ENSO recharge theory (Jin 1997) predicts that the time scale of ENSO can be decomposed into a re- and discharging time scale and a surface layer response time scale. The subtle interplay between positive air-sea feedback and the delayed negative feedback leads to a particular phase relationship between the zonally integrated thermocline depth and the interannual SSTA variations (Jin 1997). In this case the zonal mean thermocline depth leads the SSTA by several months up to a year. As can be seen from Fig. 11 our interannual ENSO oscillations are consistent with Jin's recharge paradigm: a deep zonally averaged thermocline preceeds the interannual SST anomalies in the cold tongue by almost a quarter period. The secondary peak in heat content following the warming in the sea surface temperature is due to an interaction between the fast and slow ENSO modes and the annual cycle. Further analysis (not shown) has revealed that the slow negative feedback is mostly provided by Rossby waves, whereas equatorial Kelvin waves play a crucial role in triggering El Niño and La Niña events.
Recent studies of ENSO dynamics (Gu and Philander 1995; Liu 2002) have revealed that the amplitude of ENSO variations depends in a nontrivial manner on the strength of the annual cycle. Liu (2002) found out that for large amplitudes of the annual cycle, ENSO variability tends to be weak, whereas it can grow when the amplitude of the annual cycle in the equatorial Pacific is diminished. The annual cycle serves as pacemaker for ENSO. In addition to the amplitude, the frequency, and phase of ENSO are dependent on the annual cycle forcing (Jin et al. 1994; Tziperman et al. 1994). Moreover, due to the variance enhancement of ENSO during boreal fall, the amplitude of the annual cycle is modified by changes in ENSO variability (Xie 1995). As we have seen in our previous discussion, biophysical coupling tends to reduce the amplitude of the equatorial annual cycle. This may give ENSO more freedom to set up its own variability regime (see Jin et al. 1994; Liu 2002). In order to study the interaction between ecosystem dynamics and interannual climate variations, associated with ENSO, we computed the simulated Niño-3 SST anomalies for the three experiments with $\gamma=0,0.5,1.0$ and their corresponding power spectra. The result is depicted in Fig. 12.

There is hardly any interannual variability for the case $\delta=1.5, \gamma=0.0$. For larger values of $\gamma$, mimicking stronger biophysical coupling we observe an increase in ENSO variability to realistic values, as well as a shift to larger periods. For $\gamma=0.5$ two different ENSO modes can be identified: A westward-propagating SST mode with 2-yr periodicity and rather small amplitude, and an eastward-propagating wave mode that is excited only occasionally, thereby triggering some kind of ENSO bursting behavior. The corresponding Niño-3 SSTA time series exhibits weak chaotic behavior, which may result from an interaction between the annual cycle, the biannual, and the longer-term ENSO mode. By increasing $\gamma$, the variance of biannually dominated regime diminishes and the 3-yr eastward-propagating mode takes over.

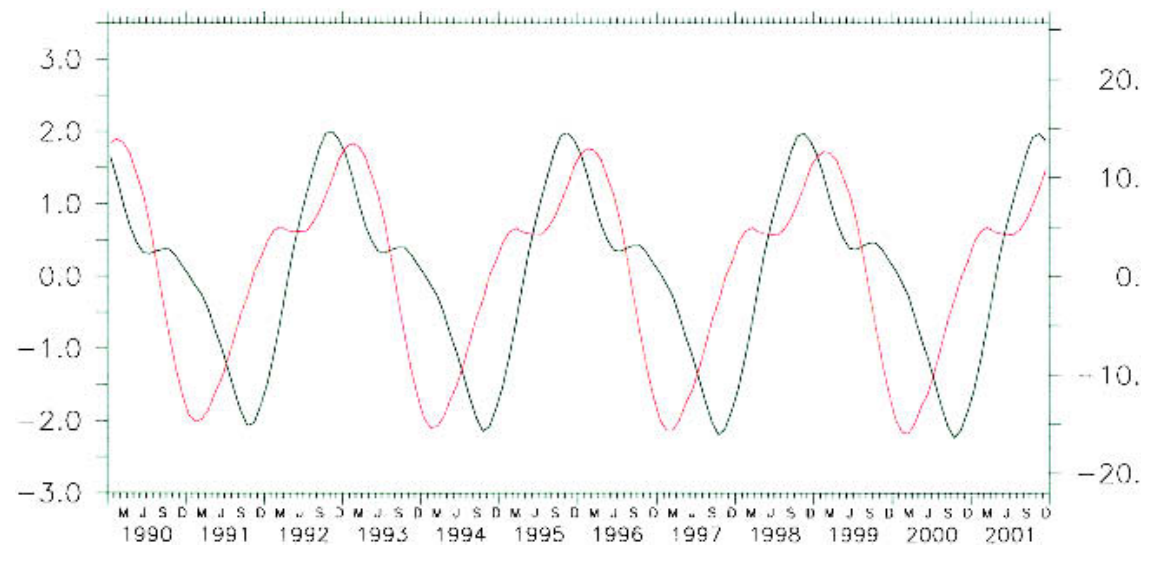

FIG. 11. Simulated Niño-3 SSTA (black) for $\delta=1.5, \gamma=1.0$, and zonally (over whole Pacific basin) and meridionally (from $2.5^{\circ} \mathrm{S}$ to $2.5^{\circ} \mathrm{N}$ ) averaged thermocline depth anomaly (red). 

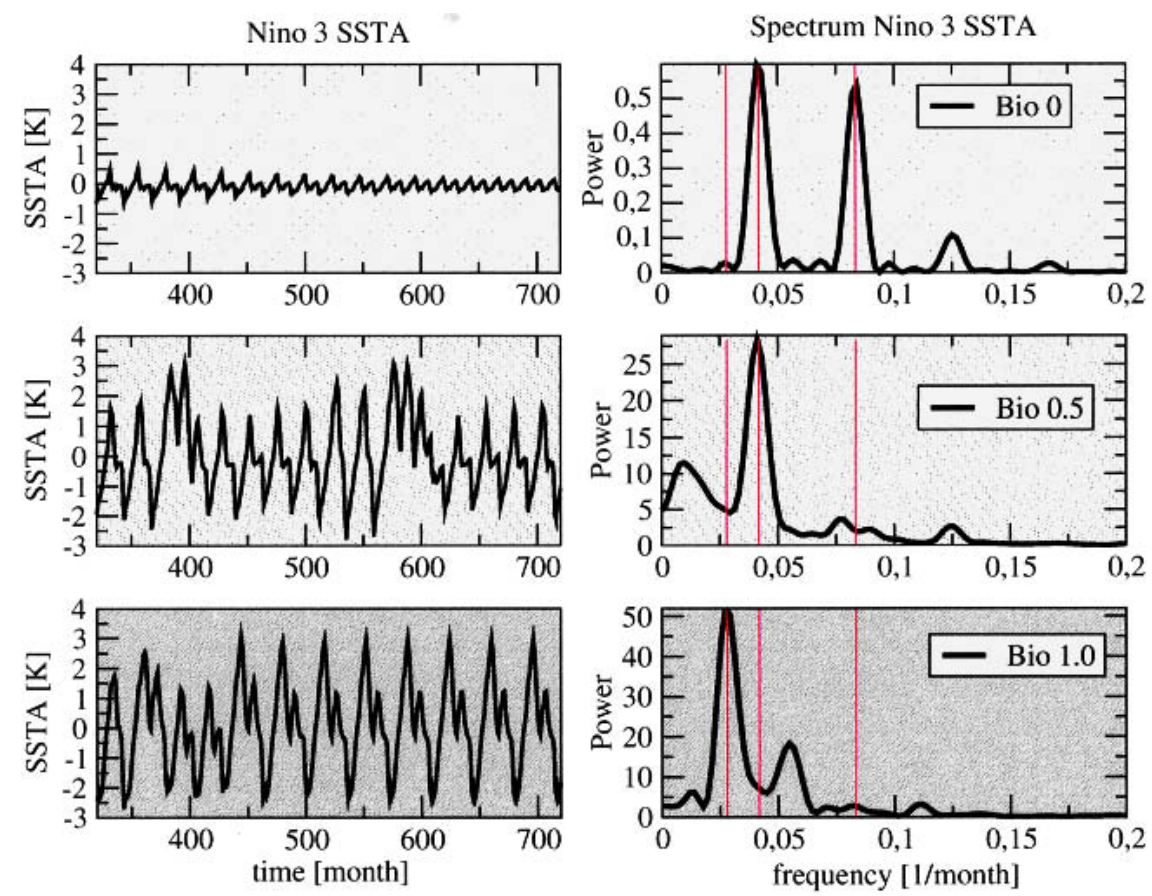

Fig. 12. (left) Niño-3 surface temperature anomalies for $\delta=1.5, \gamma=0.0,0.5,1.0$ (from top to bottom). (right) Corresponding power spectra. The vertical lines indicate integer multiple periods of the annual cycle.

After an initial spinup phase of about 480 months, the ENSO oscillation becomes periodic (see Fig. 12). The major El Niño events that occur every 36 months are perturbed by a subharmonic oscillation with a 1618-month period. This subharmonic oscillation exhibits some characteristics of a westward-propagating SST mode, seen for $\gamma=0.5$. The fact that the dominant ENSO mode is frequency-locked to multiples of the annual cycle is a clear indication that the two interact nonlinearly with each other. It should be noted here, that the statistical atmosphere was constructed in such a way that the Bjerknes feedback may change the amplitude of the annual cycle. Previous studies on ENSOannual cycle interactions by Liu (2002), Tziperman et al. (1994), and Jin et al. (1994) have revealed that the frequency, the amplitude, and the irregularity of ENSO are dependent on the strength of the annualinterannual nonlinear coupling. Our results obtained with a hybrid coupled ENSO model confirm their findings. In our simulations strongest interannual SST variations occur in the eastern equatorial Pacific. A map of the regression pattern of the simulated SST with the simulated Niño-3 SSTA (Fig. 13) shows a typical ENSO-like pattern. However, the center of action of our simulated ENSO mode is shifted slightly south of the equator, unlike in the observations.

As mentioned earlier, two distinct interannual variability regimes can be identified for $\gamma \geq 0.5$. This is further illustrated in Fig. 14, showing a phase-space view of ENSO. The red trajectory corresponds to the low-amplitude 2-yr mode regime, and it is apparent that thermocline movements do not play an important role. This mode is also characterized by westward SST propagation, typical for the SST modes of Neelin (1991). The 3-yr large-amplitude mode (blue line) involves large thermocline displacements of about $60 \mathrm{~m}$, clearly reminiscent of a mixed SST-wave mode. Of our simulations, this mode captures the features of the post1976 ENSO regime best. Furthermore, a peculiarity of our ENSO mode is that large western Pacific SST anomalies are generated. This is an artifact that may originate from the fact that only two atmospheric patterns are taken into account in our statistical atmosphere. As can be seen from Fig. 14 the SST mode and the mixed mode are connected with each other in phase space. After a major El Niño event, the ENSO system

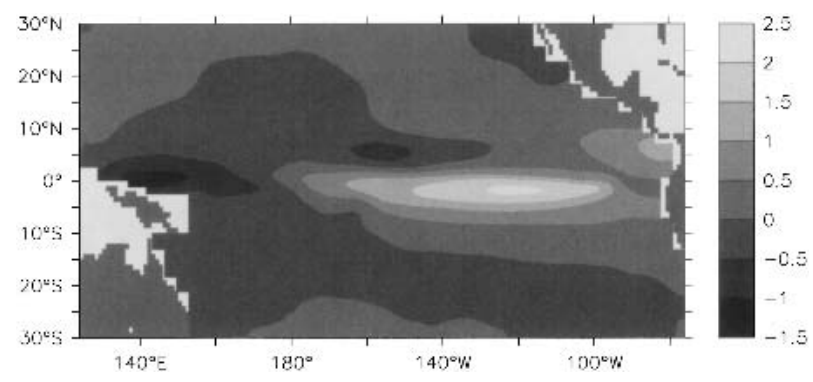

FIG. 13. Regression map of modeled SSTA (K) on Niño-3 index for $\delta=1.5, \gamma=1.0$. 


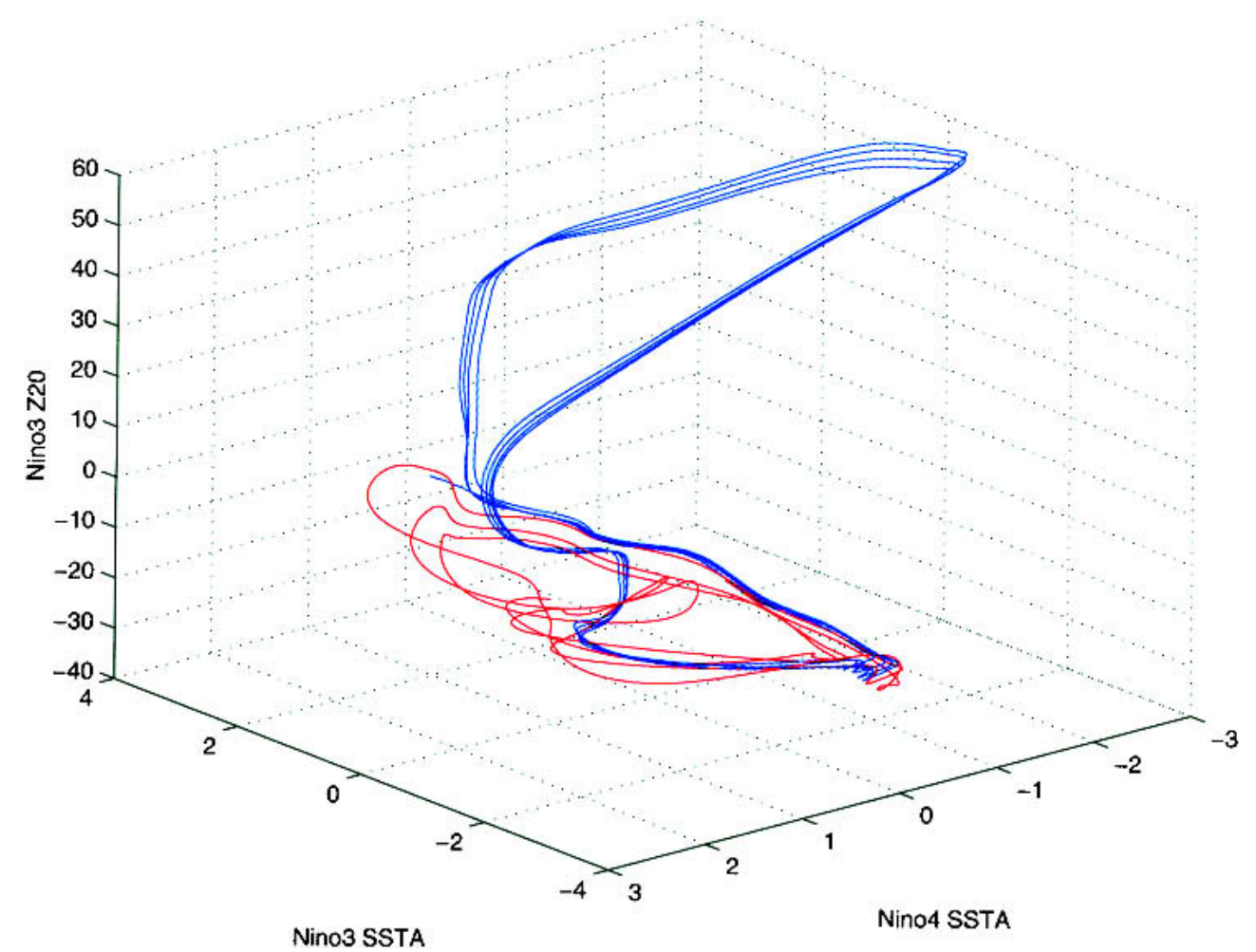

FIG. 14. Simulated phase-space diagram for Niño-3 SSTA, Niño-3 thermocline depth anomaly, and the Niño-4 SSTA for $\delta=1.5, \gamma=1.0$. The red trajectory corresponds to the low-amplitude regime of ENSO, the blue line to the large-amplitude ENSO regime, shown in Fig. 12, bottom.

returns back to the biannual mode. In contrast to the case $\gamma=0.5$, for which the system hardly leaves the biannual regime, the biophysical coupling pushes the ENSO system beyond the biannual threshold. A more detailed analysis of these variability regimes and how they are connected in phase space will be presented in a forthcoming study.

As mentioned earlier, the heating anomaly between the experiments $\gamma=0$ and $\gamma=1$ can be decomposed into a direct effect, characterizing changes of the light attenuation within the mixed layer and an indirect effect, associated with ocean dynamic heating. The direct effect and its influence on ENSO can be further separated into a part that is dominated by interannual changes of the chlorophyll concentrations and a part that reflects interannual changes of the mixed layer depth. Figure 15 displays the radiant heating along the equator from the interannual chlorophyll variations and a mean mixed layer depth, corresponding to $\gamma=$ $1.0, \delta=1.5$. We clearly see that the total range of the interannual heating anomalies amounts to about 0.3$0.5 \mathrm{~K} \mathrm{month}^{-1}$, similar to the estimates of Timmermann and Jin (2002) and Strutton and Chavez (2004). The high chlorophyll concentrations during La Niña events (about $0.4 \mathrm{mg} \mathrm{m}^{-3}$, in the eastern equatorial Pacific; see Fig. 16) lead to an enhanced absorption of solar light in the mean mixed layer. During El Niño events the chlo- rophyll concentrations are low $\left(0.05-0.2 \mathrm{mg} \mathrm{m}^{-3}\right)$, which leads to a reduction of radiant heating in a constant mixed layer. In addition, during El Niño events the mixed layer in the eastern equatorial Pacific is quite deep (about $50 \mathrm{~m}$; see Fig. 16), whereas it is shallow during La Niña events (about $20 \mathrm{~m}$ ), in agreement with the observational constraints reported by Wang and McPhaden (2000). This leads to an amplification of the direct biological effect. During La Niña events the warming tendency due to ocean biology can warm the shallow mixed layer much more effectively than during El Niño events, which are characterized by deep mixed layers.

\section{Role of the positive air-sea feedback}

In order to investigate whether the positive air-sea feedback of Bjerknes (1969) and Gill (1982) plays an important role in amplifying the biological influence on the surface heat budget, as conjectured by Timmermann and Jin (2002), we repeated the above experiments with $\gamma=0,1.0$ while keeping the coupling strength $\delta=0$. As can be seen from Fig. 7 the biophysical coupling leads to a small negative temperature anomaly in the eastern equatorial Pacific of about -0.2 $\mathrm{K}$. This finding is similar to the results of Nakamoto et 


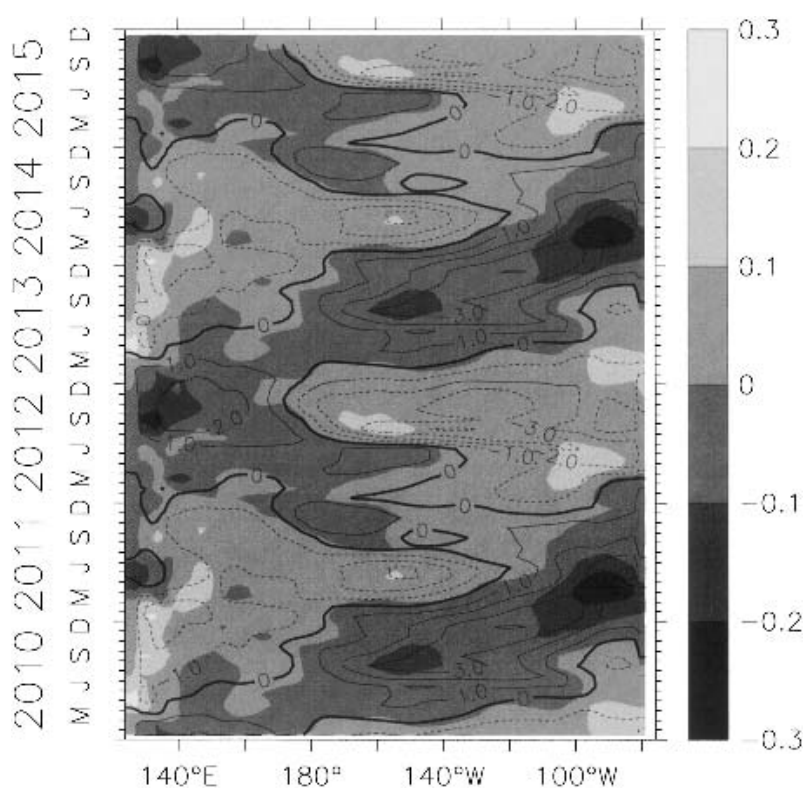

FIG. 15. Surface layer radiant heating anomaly $\left(\mathrm{K} \mathrm{month}^{-1}\right)$ computed from the interannual chlorophyll anomalies and the mean mixed layer depth (shading). Sea surface temperature anomaly (K) (contours).

al. (2001) who used a forced ocean model with a fixed attenuation depth. However, the magnitude of feedbacks in the tropical Pacific can not be assessed without accounting for the positive Bjerknes feedback. In fact,

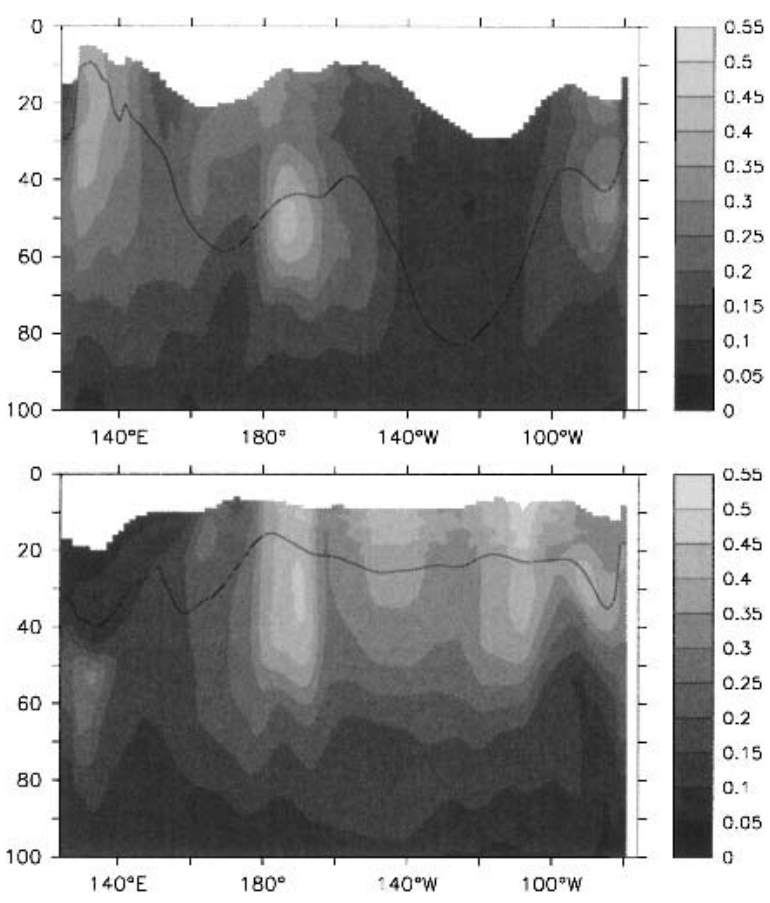

FIG. 16. Chlorophyll concentration during a mature (top) El Niño event and (bottom) La Niña event. These figures are obtained for $\delta=1.5, \gamma=1.0$. The solid lines represent the base of the mixed layer. the biophysical feedback changes even sign, when the positive air-sea coupling is taken into account (see Fig. 7 , bottom). As an example, a small temperature anomaly can be easily modified locally and by remote forcing, as shown in Fig. 1. An initial negative temperature anomaly in the central equatorial Pacific will weaken the trade winds to the east of it (Fig. 1, bottom), thereby triggering a slight warming in the eastern equatorial Pacific through a reduction in oceanic mixing, zonal advection, and equatorial upwelling. This warming anomaly will be amplified by the positive air-sea coupling in the eastern equatorial Pacific (Fig. 1, top). Subsequently this leads to a strengthening of the trade winds in the warm pool area (Fig. 1, bottom) and a cooling of the surface waters in the western Pacific, etc. This example illustrates that a temperature anomaly in the east will immediately change the temperature in the west and vice versa. Forced ocean experiments like those of Nakamoto et al. (2001) can not capture this first-order effect.

This surprising result highlights the fact that forced ocean model sensitivity experiments in the tropical $\mathrm{Pa}$ cific may provide only limited insights into intrinsically coupled climate feedbacks.

\section{Summary and discussion}

Previous observational studies (Lewis et al. 1983, 1990; Strutton and Chavez 2004) have documented that light absorption due to the concentration of photosynthetically active chlorophyll in surface waters may have a significant effect on the surface ocean heat budget in the Tropics. These studies have paved the road for a more quantitative assessment of the role of light attenuation on the surface layer heat balance using climate models (Schneider and Zhu 1998; Timmermann and Jin 2002), as well as forced ocean models (Nakamoto et al. 2001; Murtugudde et al. 2002). All of these studies come to the conclusion that phytoplankton are an important component in the surface layer heat budget of the tropical oceans. A recent review study of Miller et al. (2003) provides more details on possible biophysical feedbacks in the Pacific Ocean.

The results presented here support this general conclusion and point toward several new ideas.

- Biological heating can be decomposed into a direct (Timmermann and Jin 2002) and an indirect contribution, as suggested by (Murtugudde et al. 2002). The former originates from changes in the attenuation of light, the latter from changes of the mixed layer, associated with a deep chlorophyll maximum located just below the mixed layer. The mean mixed layer depth in the eastern equatorial Pacific changes by about $10-15 \mathrm{~m}$. A biologically induced deepening of the mixed layer is associated with a weakened southequatorial current, reduced upwelling, and hence a warmer eastern equatorial Pacific. 
- The Bjerknes (1969) feedback leads to an amplification of the biologically induced temperature changes by changing the equatorial upwelling, mixing, and the zonal currents. The net effect is a warming of the eastern equatorial Pacific by up to $2 \mathrm{~K}$ and a cooling of the western Pacific, which may be somewhat unrealistic in amplitude.

- The overall deepening of the mixed layer in the eastern equatorial Pacific and the associated increase in the heat capacity leads to a weakening of the amplitude of the annual cycle in the equatorial Pacific by about $2 \mathrm{~K}$ (see Fig. 10). However, it should be noted here, that a background annual cycle forcing is used in our coupled simulations. Changes in the annual cycle originate from mixed layer physics and the Bjerknes feedback, in accordance with the results of Xie (1994).

- The coupling coefficient between atmospheric wind stress and SST anomalies is chosen close to a bifurcation point for ENSO. This shall reflect the lack of consensus in the ENSO community regarding the question whether ENSO is stable or unstable. Admittedly, this leads to a high sensitivity of the simulated ENSO characteristics with respect to parameter changes. In a future study we plan to use a more sophisticated statistical atmosphere which captures tropical "weather noise" to study the role of ocean biological on ENSO in the stable oscillatory regime.

- The statistical characteristics of the simulated ENSO mode are very sensitive to the biological coupling factor. Without biophysical coupling a very weak biannual mode is present, which is amplified when $\gamma \geq$ 0.5 . Furthermore, as the biophysical coupling increases, intermittent regime switches can be observed between a biannual small-amplitude westwardpropagating SST mode and a 3-yr large-amplitude eastward-propagating mixed SST-wave mode. For a coupling strength of $\gamma=1$ the large-amplitude mode dominates and only weak signs of the biannual mode remain, which occur as subharmonic signals to the 3 -yr mode with a 16-18-month period. Overall, the effect of the biophysical coupling is to amplify ENSO-like variability. This behavior had been attributed to a weakening of the amplitude of the annual cycle. Although difficult to prove using our hybrid coupled ENSO model, this nonlinear explanation seems reasonable, because a too strong annual cycle forcing prohibits the development of an interannual mode (Liu 2002). The annual cycle, being subject to amplitude changes due to ocean biology, serves as a pacemaker for ENSO variability. The fact that our simulated ENSO modes are frequency-entrained to multiples of the annual cycle is a clear evidence for a 2:1 and 3:1 phase synchronization, reminiscent of typical nonlinear pacemaking mechanisms.

- Our study has revealed furthermore that oceanic sensitivities in the tropical Pacific have to be studied using coupled models. The Bjerknes feedback seems to be a crucial component of the climate system and we have found the surprising result that the Bjerknes feedback changes not only the amplitude of the biologically induced warming in the eastern equatorial Pacific but also its sign (see Fig. 8). Moreover, we found that the simulated chlorophyll concentrations in the equatorial Pacific depend strongly on $\delta$ and $\gamma$. This may be an indication that offline ecosystem models, which do not capture biophysical interactions may miss essential feedbacks. It may also be problematic to tune ecosystem models for the tropical Pacific without taking into account biophysical interactions.

We see further relevance of our study in the context of coupled climate modeling. State-of-the-art CGCM simulations tend to have a cold bias in the eastern equatorial Pacific (AchutaRao and Sperber 2002). Taking into account the interaction between ocean thermodynamics and ecosystem dynamics may help to remove the typical cold bias of CGCM, as suggested by Murtugudde et al. (2002) and Timmermann and Jin (2002). Studies with coupled GCM-ecosystem models are under way (O. Aumont 2003 and E. Maier-Reimer 2003, personal communications) and it still remains to be shown whether our results obtained with a hybrid coupled tropical model can be confirmed.

Recent compiled evidence (Chuey et al. 1987) suggest that the climate of the Last Glacial Maximum (LGM, 21000 years ago) was characterized by stronger Pacific trade winds, increased equatorial upwelling, and steeper thermocline slopes (Andreasen and Ravelo 1997). This may have led to an increase of biological productivity in the eastern equatorial Pacific. We therefore expect that biophysical feedbacks may have been particularly strong during this period. A study of the LGM biofeedbacks will be performed in a forthcoming study, by changing the boundary conditions of our hybrid coupled tropical model to LGM background conditions, simulated by a global coupled climate model.

One important caveat of our coupled ocean and ecosystem model is that its individual components such as the ocean model and the ecosystem model were tuned first to simulate the oceanic and biological states in an optimal manner. The Bjerknes feedback and the biophysical coupling were neglected. Hence, by allowing for $\gamma, \delta \neq 0$ the coupled simulation differs from the optimized state, and may hence be more unrealistic than the ocean-only model simulations. In future, an effort will be made to tune the hybrid coupled model to reality and repeat these experiments. In that respect our study should be regarded more as an order of magnitude estimation for the biophysical coupling effect, rather than a most realistic assessment of its role.

Moreover, important physical processes in the eastern and central tropical Pacific are not resolved properly in our model simulations, such as tropical instability waves. Tropical instability waves play an important 
part in determining the eastern equatorial climatic mean state in the Pacific (Vialard et al. 2001). They contribute approximately $2 \mathrm{~K}$ month $^{-1}$ heating to the tropical heat budget. In addition, these waves are accompanied by large upwelling anomalies. Associated high nutrient concentrations in the cores of these waves lead to very large phytoplankton blooms, in particular during La Niña years, such as 1998. This will lead to changes also in the radiant heating. It is expected that the net effect of these high-frequency bioclimate feedbacks is comparable in size to the low-frequency changes discussed in our study. Further analysis will illuminate the role of tropical instability waves for the biologically induced heating of the eastern equatorial Pacific.

Summarizing, we have presented first evidence using a coupled model that ocean biology has an effect on the climate mean state, the annual cycle in the tropical $\mathrm{Pa}-$ cific, as well as on ENSO. The eastern equatorial $\mathrm{Pa}$ cific warms by about $2 \mathrm{~K}$. The heating can be decomposed into a direct and indirect effect (Murtugudde et al. 2002), both contributing equally to the warming (see Figs. 5 and 7). Quantitatively our study agrees with the most recent observational estimates of biologically induced heating rates in the tropical Pacific by Strutton and Chavez (2004).

Acknowledgments. This work was supported by the Deutsche Forschungsgemeinschaft (DFG) through a young researcher's grant. During his visit to Hawaii, B. Marzeion was supported by the DAAD scholar exchange program. F.-F. Jin is supported by a NOAA Grant GC01246 and a NSF Grant ATM0226141. This work was strongly inspired by a workshop on bioclimate feedbacks held at SIO and organized by Dr. A Miller.

\section{REFERENCES}

AchutaRao, K., and K. R. Sperber, 2002: Simulation of the El Niño Southern Oscillation: Results from the Coupled Model Intercomparison Project. Climate Dyn., 19, 191-209.

Andreasen, D., and A. C. Ravelo, 1997: Tropical Pacific Ocean thermocline depth reconstructions for the last glacial maximum. Paleoceanography, 12, 395-414.

Bjerknes, J., 1969: Atmospheric teleconnections from the equatorial Pacific. Mon. Wea. Rev., 97, 163-172.

Burgers, G., and G. J. van Oldenborgh, 2003: On the impact of local feedbacks in the central Pacific on the ENSO cycle. $J$. Climate, 16, 2396-2407.

Chavez, F. P., P. G. Strutton, and M. J. McPhaden, 1998: Biological-physical coupling in the equatorial Pacific during the onset of the 1997-98 El Niño. Geophys. Res. Lett., 25, 35433546.

, 一, G. E. Friederich, R. A. Feely, G. C. Feldman, D. G. Foley, and M. J. McPhaden, 1999: Biological and chemical response of the equatorial Pacific Ocean to the 1997-98 El Niño. Science, 286, 2126-2131.

Chen, D., L. M. Rothstein, and A. J. Busalacchi, 1994: A hybrid vertical mixing scheme and its application to tropical ocean models. J. Phys. Oceanogr., 24, 2156-2179.

Christian, J. R., M. A. Verschell, R. Murtugudde, A. J. Busalacchi, and C. R. McClain, 2001a: Biogeochemical modelling of the tropical Pacific Ocean. I. Seasonal and interseasonal variability. Deep-Sea Res., 49B, 509-543.

,,,,---- and,$- 2001 \mathrm{~b}$ : Biogeochemical modelling of the tropical Pacific Ocean. II. Iron biogeochemistry. Deep-Sea Res., 49B, 545-565.

Chuey, J., D. Rea, and N. Pisias, 1987: Late pleistocene paleoclimatology of the central equatorial Pacific: A quantitive record of eolian and carbonate deposition. Quat. Res., 28, 323339.

Cowles, T. J., and R. T. Barber, 1977: Biological consequences of the 1975 El Niño. Science, 195, 285-287.

Eckert, C., 1998: On predictibility limits of ENSO. Ph.D. thesis, Max-Planck-Institut für Meteorologie, $77 \mathrm{pp}$.

Flügel, M., 1994: Untersuchungen zu Mechanismus und Vorhersagbarkeit von ENSO mit einem vereinfachten gekoppelten Ozean-Atmosphäre-Modell (Investigating the mechanisms and predictability of ENSO using a simplified coupled oceanatmosphere model). Ph.D. thesis, Max-Planck-Institut für Meteorologie, $81 \mathrm{pp}$.

Gent, P. R., and M. A. Cane, 1989: A reduced gravity, primitive equation model of the upper equatorial ocean. J. Comput. Phys., 81, 444-480.

Gill, A. E., 1982: Atmosphere-Ocean Dynamics. Academic Press, $662 \mathrm{pp}$.

Gu, D., and S. G. H. Philander, 1995: Secular changes of annual and interannual variability in the Tropics during the past century. J. Climate, 8, 864-876.

Jin, F., 1997: An equatorial ocean recharge paradigm for ENSO. Part I: Conceptual model. J. Atmos. Sci., 54, 811-829.

Jin, F.-F., J. Neelin, and M. Ghil, 1994: El Niño on the Devil's Staircase: Annual subharmonic steps to chaos. Science, 264, 70-72.

Kaplan, A., M. Cane, Y. Kushnir, M. Blumenthal, and B. Rajagoplan, 1998: Analysis of global sea surface temperature 1856-1991. J. Geophys. Res., 103, 18 567-18 589.

Kessler, W., 2002: Is ENSO a cycle or a series of events? Geophys. Res. Lett., 29, 2125, doi:10.1029/2002GL015924.

- L. Rothstein, and D. Chen, 1998: The annual cycle of SST in the eastern tropical Pacific, diagnosed in an ocean GCM. $J$. Climate, 11, 777-799.

Latif, M., and Coauthors, 2001: ENSIP: The El Niño Simulation Intercomparison Project. Climate Dyn., 18, 255-276.

Leonard, C. L., and C. R. McClain, 1996: Assessment of interannual variation (1979-1986) in pigment concentrations in the tropical Pacific using the CZCS. Int. J. Remote Sens., 17, 721732.

Lewis, M. R., J. J. Cullen, and T. Platt, 1983: Phytoplankton and thermal structure in the ocean: Consequences of nonuniformity in chlorophyll profile. J. Geophys. Res., 88, 2565-2570.

_, M. Carr, G. C. Feldman, W. Esias, and C. McClain, 1990: Influence of penetrating solar radiation on the heat budget of the equatorial Pacific. Nature, 347, 543-546.

Li, T., and S. G. H. Philander, 1996: On the annual cycle of the equatorial eastern Pacific. J. Climate, 9, 2986-2998.

Liu, Z., 2002: A simple model study of the forced response of ENSO to an external periodic forcing. J. Climate, 15, 10881098.

Miller, A. J., and Coauthors, 2003: Potential feedbacks between Pacific Ocean ecosystems and interdecadal climate variations. Bull. Amer. Meteor. Soc., 84, 617-633.

Morel, A., 1988: Optical modeling of the upper ocean in relation to its biogenous matter content (case 1 waters). J. Geophys. Res., 93, $10749-10768$.

Murtugudde, R., R. Seager, and A. J. Busalacchi, 1996: Simulation of the tropical oceans with an ocean GCM coupled to an atmospheric mixed layer model. J. Climate, 9, 1795-1815.

- S. Signorini, J. Christian, A. Busalacchi, and C. McClain, 1999: Ocean color variability of the tropical Indo-Pacific ba- 
sin observed by SeaWiFS during 1997-1998. J. Geophys. Res., 104, $18367-18382$.

— J. Beauchamp, and A. Busalacchi, 2002: Effects of penetrative radiation the upper tropical ocean circulation. J. Climate, 15, 470-486.

Nakamoto, S., S. P. Kumar, J. M. Oberhuber, J. Ishizaka, K. Muneyama, and R. Frouin, 2001: Response of the equatorial Pacific to chlorophyll pigment in a mixed layer isopycnical ocean general circulation model. Geophys. Res. Lett., 28, 2021-2024.

Neelin, D., 1991: The slow sea surface temperature mode and the fast-wave limit: Analytical theory for tropical interannual oscillations and experiments in a hybrid coupled model. J. Atmos. Sci., 48, 584-606.

Sathyendranath, S., A. D. Gouveia, S. R. Shetye, P. Ravindran, and T. Platt, 1991: Biological control of the surface temperature in the Arabian Sea. Nature, 349, 54-56.

Schneider, E., and Z. Zhu, 1998: Sensitivity of the simulated annual cycle of sea surface temperature in the equatorial Pacific to sunlight penetration. J. Climate, 11, 1932-1950.

Seager, R., S. E. Zebiak, and M. A. Cane, 1988: A model of the tropical Pacific sea surface temperature climatology. J. Geophys. Res., 93, 1265-1280.

Stricherz, J. N., D. M. Legler, and J. J. O’Brien, 1997: Tropical Pacific Ocean. Vol. 2, TOGA Pseudo-Stress Atlas 1985-1994, COAPS Rep. 97-2, Florida State University, 163 pp.
Strutton, P. G., and F. P. Chavez, 2004: Biological heating in the equatorial Pacific: Spatial and temporal variability. J. Climate, 17, 1097-1109.

Timmermann, A., and F.-F. Jin, 2002: Phytoplankton influences on tropical climate. Geophys. Res. Lett., 29, 2104, doi:10.10129/2002GL015434.

Tziperman, E., L. Stone, M. A. Cane, and H. Jarosh, 1994: El Niño chaos: Overlapping of resonances between the seasonal cycle and the Pacific ocean-atmosphere oscillator. Science, 264, $72-74$.

Vialard, J., C. Menkes, J.-P. Boulanger, P. Delecluse, E. Guilyardi, M. McPhaden, and G. Madec, 2001: A model study of oceanic mechanisms affecting equatorial Pacific sea surface temperature during the 1997-98 El Niño. J. Phys. Oceanogr., 31, 1649-1675.

Wang, W., and M. McPhaden, 2000: The surface layer heat balance in the equatorial Pacific Ocean. Part II: Interannual variability. J. Phys. Oceanogr., 30, 2989-3008.

Xie, S., 1994: On the genesis of the equatorial annual cycle. $J$. Climate, 7, 2008-2013.

_ 1995: Interaction between the annual and interannual variations in the equatorial Pacific. J. Phys. Oceanogr., 25, 19301941.

1996: Westward propagation of latitudinal asymmetry in a coupled ocean-atmosphere model. J. Atmos. Sci., 53, 32363250 